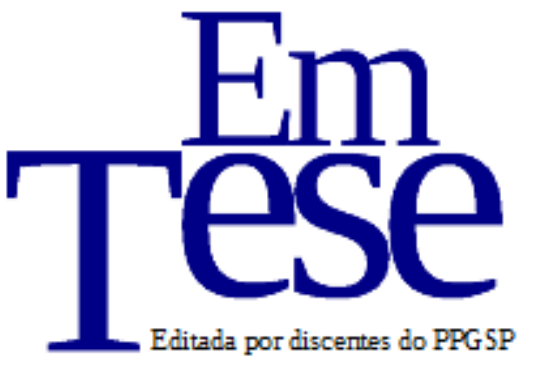

UFSC

PPG SP PROG RAMA DE

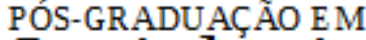

Sociologia Política

V. 15, n. 2 p. 01, Julho, 2018.

DOI: http://dx.doi.org/10.5007/1806-5023.2018v15n2p57

\title{
A contribuição neokantiana para a fundação das ciências sociais ${ }^{1}$
}

Iann Endo Lobo ${ }^{2}$

Resumo: O presente artigo pretende tratar da importância do pensamento neokantiano para o desenvolvimento das ciências sociais. Para tanto, foca nas ideias de alguns pensadores da escola neokantiana de Baden, sobretudo, Wilhelm Windelband e Heinrich Rickert, enquanto analisa a influência dessa escola na sociologia weberiana, principalmente no que tange seu aspecto epistemológico e metodológico. Assim, o artigo é dividido em três partes. A primeira se concentra na contextualização histórica e nos problemas gerais com os quais se depara o neokantismo. Enquanto a segunda visa analisar o modo como Rickert e Windelband categorizam os diferentes tipos de conhecimento e formas de saberes científicos, apontando as afinidades dos teóricos com Weber. Por fim, a terceira seção se encarrega de analisar a discussão acerca da relação entre ciência e valores, segundo Rickert, novamente evidenciando sua importância na fundamentação da sociologia weberiana.

Palavras-chave: Valor, Neocriticismo, Epistemologia, Weber, Rickert.

\section{The neokantian contribution in the foundation of the social sciences}

\begin{abstract}
The present article intends to deal with the importance of the neokantian thought for the development of the social sciences. In order to do so it focuses in the ideas of some thinkers from neokantian school, overall, Wilhelm Windelband and Heinrich Rickert, while analyses the influence of that school in the weberian sociology, mainly in its epistemological and methodological aspects. Thus, the article is separated in three parts. The first concentrates in the historical contextualization and in the general problems wich neokantianism faces. The second intends to analyse how Rickert and Windelband categorize the different types and means of scientifical knowledge, pointing to the affinities the theorists have in relation to Weber. Finally, the third section takes care of the discussion about the relationship between science and values,according to Rickert, emphasizing again itsrole in the foundation of the weberian sociology.
\end{abstract}

Keywords: Valor, Neocriticism, Epistemology, Weber, Rickert.

\footnotetext{
1 (c) Er Er obra está licenciada com uma Licença Creative Commons Atribuição 4.0 Internacional. ${ }^{2}$ Mestrando em Sociologia Política UFSC - PPGSP (Programa de Pós-Graduação de Sociologia Política). Área de teoria política e social. E-mail: iannloboe@gmail.com
} 


\section{Introdução}

Os cursos de sociologia, de modo geral, dão primazia aos teóricos da clássica trindade, Marx, Durkheim e Weber. Porém, em função da limitação temporal, falta, por vezes, nas bibliografias de estudos, os autores que antecederam os clássicos. Não cabe questionar a importância da valorização dos clássicos na formação sociológica, quer-se apenas evidenciar as vantagens do conhecimento da tradição e história do pensamento social para a compreensão mesma dos clássicos. A biologia busca compreender a gênese de um fruto, tendo em vista aquilo que o antecede, a árvore como um todo, suas raízes, seiva e folhas, do mesmo modo o entendimento da gênese dos conceitos pode favorecer a justa apreensão das teorias clássicas.

A ciência natural pode mais facilmente passar por seus antepassados como degraus que já não tem mais interesse para o estágio recente de sua disciplina. Um astrônomo pode estudar seu objeto através dos mais desenvolvidos meios sem conhecimento algum do que era pensado sobre isso há duzentos anos. Contudo, as ciências sociais não gozam de tamanha autonomia com relação às gerações anteriores. Seja por força ou fraqueza, fato é que qualquer estudo da cultura e da história passaria muito mal sem travar diálogo com rica herança teórica que a precede.

Assim, o presente artigo visa discutir a importância que a escola neokantiana teve na formação do pensamento sociológico. Para isso, apresenta um panorama contextual da gênese desse movimento intelectual a fim de compreender seu sentido na história das ideias. Em seguida, analisa as contribuições de Heinrich Rickert e Wilhelm Windelband, dois representantes da escola neokantiana de Baden, para a fundamentação das ciências. Por fim, demonstra como o pensamento de Weber foi significativamente influenciado pelas ideias neokantianas, sobretudo, por Rickert.

As dificuldades na pesquisa dessa tradição são grandes. Esse fato é constatado pela escassez de trabalhos sobre o tema, inclusive na Alemanha falta um trabalho de resgate e preservação das obras e correspondências dos mais célebres representantes dessa escola (BEISER, 2014, p. 8). Aliás, no Brasil são raras, quando existem, as traduções das obras de Rickert, Windelband e Hermann Cohen, para citar apenas alguns nomes. A despeito desse silêncio injustificado, a importância do neokantismo na história do pensamento ocidental vem sendo recuperada nos meios acadêmicos anglófonos, nos quais se constata a escalada no 
número de livros e comentários sobre o assunto ${ }^{3}$. Foucault (1994, v. II, p. 546, apud ALVES, 2007) apontou certa vez que devido a herança crítica via Kant, todos [pensadores contemporâneos] somos neokantianos. E é conhecida a influência que sociólogos da estatura de Weber e Simmel tiveram desse movimento.

Além de terem sido amigos pessoais e terem trabalhado em prol da consolidação institucional e epistemológica da nascente ciência sociológica, Weber e Simmel partiam da comum influência do neokantismo, sobretudo por uma linha específica dessa matriz teórica. A extensão da influência chega aos mais diversos aspectos das ideias dos autores, desde seus princípios propedêuticos, passando por sua noção de História e método de pesquisa. Tendo de escolher, por razões puramente práticas, entre um desses dois grandes sociólogos, o artigo optou por apontar alguns aspectos da relação entre o neokantismo e Weber. Antes de adentrar na relação com Weber, cabe perguntar do que se trata o movimento intelectual neokantiano? Quais dilemas ele visou responder?

\section{A escola neokantiana}

“Zurück zu Kant!", retorno ou volta a Kant, é a palavra de ordem conhecida como o mote do neokantismo, foi lançada por Eduard Zeller (1814-1908) na sua aula inaugural em 1862. Três anos depois outro expoente do movimento, Otto Liebmann (1840-1912), tomaria essas palavras como o fechamento exortativo de seu livro Kant e o epígono (Kant und die Epigonen). A década de 1860 marcou o período de consolidação do neokantismo. Contudo, o embrião do movimento em direção à Kant já vinha desde antes sendo gestado. Na segunda e terceira décadas do século XIX iniciava-se essa retomada em oposição ao idealismo alemão e da hegemonia hegeliana que pairava sobre a Alemanha (WARREN; STAITI, 2015, p.3).

O neokantismo está longe de ser um movimento homogêneo, ao longo dos anos em que sobreviveu com maior vitalidade, de 1860 até 1914, manifestou-se em diferentes matizes e estendeu-se a diversas áreas do conhecimento. Os principais polos onde se desenvolveu foram na escola de Marburg e na escola do sudoeste ou de Baden. A primeira teve em Hermann Cohen (1842-1918), Paul Natorp (1854-1924) e Ernst Cassirer (1874-1945) seus mais proeminentes representantes; a última foi protagonizada sobremaneira por Wilhelm

\footnotetext{
3 Para citar alguns exemplos, temos: The Kantian legacy in nineteenth-century science (FRIEDMAN; NORDMANN, 2006), The Genesis of Neo-Kantianism (BEISER, 2014), Neo-Kantianism in contemporary philosophy (MAKREEL; LUFT, 2009), The rise of Neo-Kantianism (KÖHNKE, 1991) e New approaches to Neo-Kantianism (WARREN; STAITI, 2015).
} 
Windelband e Heinrich Rickert. Weber, assim como Simmel, são influenciados principalmente pela escola de Baden (VANDERBERGHE, 2005, p. 57).

Esse movimento é conhecido por suas contribuições no campo da teoria do conhecimento (Erkenntnistheorie). Mais importante que a ontologia e a metafísica era, para esses autores, a questão das possibilidades e limites da cognição humana. A filosofia, nesse sentido, é submetida ao rigor e à utilidade da ciência, enquanto meio de conferir a validade (Geltung) de veracidade aos conceitos. Daí que o criticismo kantiano foi apropriado para a compreensão dos princípios de cognição e da relação entre sujeito e objeto de conhecimento. Segundo a formulação rickertiana a filosofia seria a "ciência das ciências" (Wissenschaft der Wissenschaft), enquanto o saber estaria relacionado aos modos de conhecer e, portanto, a validade do conhecimento (RICKERT, 1922, p. 1, apud WU, 2010, p. 180).

A preocupação de primeira ordem com as questões epistemológicas conduziu diversas das críticas contra o neokantismo. Heidegger que havia sido aluno de Rickert acabou por se tornar um de seus grandes adversários. O filósofo rotulou o movimento como uma "filosofia de cátedra". Argumentou que na operação de redução da filosofia a mera Erkenntnistheorie, estaria esquecida a questão pelo ser. O conhecimento do conhecimento é diferente do conhecimento em si, daquilo que é. A experiência do mundo circundante é anterior à apreensão lógica científica dos objetos que se apresentam. Essa experiência mais originária com as coisas permitiria uma relação não apenas catedrática e teorética objetificadora do real, mas uma vivência primordial do mundo circundante. Por essa via crítica, que não aprofundaremos aqui, que a fenomenologia hiedeggeriana desdobra o diálogo tenso com o neokantismo (WU, 2010, p. 186).

Lukács, desde uma perspectiva diferente de Heidegger, também criticou o movimento, que em sua avaliação foi "totalmente insignificante para a história da filosofia" (1980, p. 322 apud WARREN; STAITI, 2015, p. 4). Esse ataque passa por todo o aparato teórico político de viés marxista. Não é de surpreender que uma escola preocupada essencialmente com as questões epistemológicas e científicas pareça estranha e censurável ao ponto de vista da “filosofia da práxis", voltada antes para a unidade entre teoria e a ação política no mundo. Nesse sentido, pensa Lukács, o neokantismo é um saber puramente acadêmico e estéril, desvinculado dos acontecimentos políticos e das questões do mundo histórico concreto.

Frente ao bombardeio de críticas, cuja lista é maior do que citamos, torna-se compreensível (o que é diferente de justificável), o fato de faltar em nossos currículos bibliografias de disciplinas de teoria social um foco maior sobre o neokantismo. A causa disso, segundo alguns autores, se encontra na crença de um desenvolvimento teleológico da 
história do pensamento que passa por certos estágios. Primeiro, de Kant a Hegel; depois, pelos filósofos da suspeita, Marx, Nietzsche e Freud; para desaguar em seus desdobramentos contemporâneos com a filosofia analítica, filosofia continental ou pragmatismo (WARREN; STAITI, 2015, p. 4).

É necessário, contudo, a compreensão das razões histórico-contextuais de surgimento e desenvolvimento do neocriticismo. Sem isso, estamos longe de entender sua importância para a história do pensamento. As ciências do espírito passaram por radicais disputas metateóricas ao longo do século 19, cuja repercussão é sentida até hoje. O neokantismo foi uma dentre tantas partes desse litígio teórico.

Essa atmosfera intelectual foi marcada pela crise do idealismo hegeliano. O sistema hegeliano havia alçado às alturas os limites e atribuições da filosofia, além de ter introduzido sub-repticiamente a metafísica na história. Dessa forma postulava a identidade entre o real e o racional. O idealismo especulativo vislumbrava ainda a articulação das mais diversas disciplinas em um grande sistema teórico explicativo englobante, no qual a história é compreendida por meio de conceitos como "razão, ideia e espírito, definindo a história universal como a narrativa unificada das diversas contradições envolvendo culturas e individualidades" (WU, 2010, p. 2). No fértil solo preparado por essa conjuntura de ideias se desenvolve em competição com outras escolas as linhas do neokantismo.

Dentre os opositores destacam-se de forma geral o positivismo, o naturalismo e o historicismo. O primeiro entendia a ciência social como a ciência mãe, o coroamento do conjunto de todos os outros saberes. E não distinguia seu método daquele das ciências naturais, denominando-a "física social", a maneira de Comte. Além disso, mantinha, seguindo o aparato hegeliano, uma perspectiva teleológica da História, distinta em fases evolutivas específicas pelas quais todas as sociedades teriam de passar.

O naturalismo sofre das mesmas deficiências, imputando ao social os métodos da pesquisa natural e descriminando leis do progresso humano. Hughes (1980, p. 25) também lê o naturalismo sob a égide do positivismo. Por fim, o historicismo foi alvo dos neocriticistas graças a sua tendência particularista focada nas determinações específicas de cada situação ou objeto circunscrito em sua própria individualidade. Também se escorava na ideia ingênua de que o conhecimento, a fim de lograr validade científica devesse provir de uma investigação destituída de valores.

Recuperando os princípios da revolução copernicana operado por Kant, os neocriticistas polemizaram com essas posições pelo fato de faltarem com a questão pelos 
critérios transcendentais de cognição e, entre outros pontos, pela desconsideração da determinação dos valores na pesquisa científica.

Sua tarefa foi a de circunscrever o limite das ciências e avaliar seus princípios de validação. Trazem à baila temas como a formulação de conceitos, limites do conhecimento científico, especificidade de cada ciência, influência dos valores e da subjetividade no processo de apreensão do saber objetivo. Weber encontrou nesses autores a fonte para problematizar as bases de sua fundação epistemológica e consequentemente também os métodos de sua pesquisa histórica e cultural. Principalmente ideias vindas da escola de Baden forneceram inspiração para a teoria weberiana.

\section{A separação entre as ciências}

A relação estreita entre Weber e o criticismo se mostra de forma clara na questão da especificidade dos modos de conhecimento de cada ciência. Os representantes da escola de Baden dividiram as ciências entre dois polos, o generalizante e o individualizante.

Windelband havia buscado "renovar o projeto kantiano avançando além de Kant e, para isso, ao invés de uma unificação das ciências pelo método matemático-natural proposto por Cohen [...] pretendia garantir às ciências da natureza e às ciências do espírito a sua especificidade" (WU, 2010, p. 178), daí sua distinção entre conhecimento nomotético (Gesetzeswissenschaften) e o ideográfico (Ereigniswissenschaften). Rickert, ex-aluno e discípulo de Windelband, argumentou no mesmo sentido. Segundo ele, as ciências generalizantes tratam de nomear leis gerais a partir das relações que os objetos estabelecem entre si, como é o caso da mecânica; enquanto a individualizante pretende um conhecimento "individual” de certos fenômenos, como faz a ciência histórica. Entre os dois polos, da mecânica e da história, existe uma linha na qual se localizam as outras disciplinas, química, biologia, ciências sociais, psicologia, etc., definidas como ciências híbridas (WAGNER; HÄRPFER, 2015, p. 171).

Vale lembrar que a separação entre as formas de conhecimento está longe da divisão dos objetos em planos ontológicos distintos, e pretende apenas argumentar pela dupla via de apreensão lógica dos fenômenos, por vezes complementares (HUGHES, 1980, p. 73). Weber, que fundamentou sua ciência social nas premissas neokantianas, avançou tanto pela via generalizante quando a individualizante. A objetividade do conhecimento na ciência social, segundo o sociólogo, se desenvolve por meio dos dois processos. 
A ciência natural e a histórica são ambas, segundo pensava Rickert, conhecimentos empíricos. Elas investigam objetos através da percepção e dos sentidos. A apreensão cognitiva dos objetos da realidade é sempre seletiva, parcial e simplificadora. Dado o postulado da impossibilidade de acesso ao saber apriorístico das coisas, o meio pelo qual o sujeito identifica o objeto se dá por meio dos conceitos. A formulação dos conceitos se diferencia na medida da demanda de seu objeto específico. Por isso, a preocupação expressada por Rickert com a fundamentação da construção conceitual, uma tarefa filosófica por excelência.

Os conceitos na ciência natural são formados a partir das generalizações de fenômenos. Quão mais universal e aplicável as mais diversas situações, tão mais eficaz é o conceito científico natural, como as leis da física. Para as leis da gravidade, por exemplo, parte-se de um corpo em interação com outros corpos, observa-se as grandezas que influem na mútua atração, como massa e distância e tem-se uma fórmula universal, uma lei geral e explicativa. Essa simplificação generalizante dissolve as diversidades qualitativas das coisas (WAGNER; HÄRPFER, 2015, p. 173).

A ciência histórica, em contraste, visa ao conhecimento de um objeto em sua singularidade. O varguismo (Getúlio Vargas), por exemplo, refere-se a um movimento cujo valor diz respeito ao desenvolvimento de todo um país. A forma de sua compreensão é através das sequências causais únicas que o possibilitaram. Nesse sentido, a substância dos conceitos para a história é definida na formulação de proposições que "articulam o conhecimento da coisa investigada em sua significante individualidade". Essas formulações "clamam por validade geral e tem a forma lógica de conceitos individuais relacionais" (WAGNER; HÄRPFER, 2015, p. 174). Não expressam, portanto, leis em fórmulas gerais, mas conceitos individuais universalmente válidos de objetos singulares.

Weber se alinha a teoria da ciência rickertiana em diversos aspectos. Concorda que frente a multiplicidade infindável do real, o conhecimento das coisas se dá por meio de conceitos. E que o conhecimento histórico é ideográfico ou individualizante, assim como argumenta em seu texto sobre a objetividade nas ciências sociais:

Quando se trata da individualidade de um fenômeno, o problema da causalidade não incide sobre leis, mas sobre conexões causais concretas; não se trata de saber a que fórmula se deve subordinar o fenômeno a título de exemplar, mas sim a que constelação particular deve ser imputado como resultado (p. 54). 
E, de modo categórico, definiu o objetivo do cientista da cultura: "Aspiramos ao conhecimento de um fenômeno histórico, isto é, significativo na sua especificidade" (2006, p. $53)$.

Mas, como deve fazer o bom discípulo, Weber procurou superar seus mestres. Distanciou-se de Rickert, ao passo que se afastou da posição, segundo a qual, "a formação de conceitos gerais e abstratos, o conhecimento das regularidades, e a formulação e conexões determinadas por leis não tem justificação na ciência cultural" (WAGNER; HÄRPFER, 2015, p. 182). EM outras palavras, para Weber a formulação das leis gerais, apesar de não ser um fim, em si mesma, da ciência da cultura, é um meio instrumental importante de conhecimento que orienta o intelecto em direção ao entendimento causal da realidade social. Portanto, o saber nomológico das regularidades e conceitos abstratos tem sua parte significativa na ciência da cultura. Pois, a constatação de relações causais entre os objetos históricos, requer a utilização do conhecimento das "regularidades das conexões causais" (WEBER, 2006, p. 55).

Em seu estudo, por exemplo, sobre o capitalismo, Weber procurou compreender seu objeto qualitativamente em sua particularidade. Operou o método individualizante e circunscreveu seu objeto na diferença com relação a outros modos de vida econômica. Por outro lado, na pesquisa pela gênese do capitalismo, empregou o "princípio de causalidade, que busca estabelecer relações entre os fenômenos", característico do método generalizante. Dessa forma, apontou como a crença e o hábito protestante foram causas fundamentais para originar o capitalismo moderno (SELL, 2002, p. 105).

Em suma, pode-se afirmar que apesar de ter se apropriado de modo criativo das categorias neokantianas da separação entre as ciências, tendo incorporado ambos os métodos, individualizante e generalizante, o pensamento de Weber, sobretudo, no que tange a questão de epistemologia e método da ciência social está em grande débito com a escola de Baden.

\section{A ciência dos valores e os valores na ciência}

Mais um ponto de contato entre Rickert e Weber que vale ser notado é o papel determinante que, na opinião de ambos, os valores desempenham na ciência, sobretudo à ciência social ou histórica. Essa ideia a princípio soa estranha ao ouvido destreinado. Afinal, como deveriam os valores intervir no processo imparcial de produção de conhecimento? Esse fato não colocaria em questão o princípio de imparcialidade do conhecimento? Não para Rickert. Apesar de a ciência mover-se em vista de certos valores isso não compromete a 
validade de seu conhecimento. Rickert argumenta pelos dois caminhos "a dependência com relação a valores na ciência e a possibilidade de objetividade" (BEISER, 2011, p. 411).

Vale relembrar que tanto Rickert quanto Weber se opunham a ingenuidade de outras correntes teóricas que pressupunham o conhecimento científico como uma prática isenta de valores. A fim de resolver o problema da objetividade do conhecimento, Rickert, entre outras estratégias menores, opera a distinção, que Weber se apoiará fortemente, entre juízo de valor (Werurteil) e relação ou referência a valores (Wertbeziehen). Emitir um valor denota a reprovação ou aprovação de algo, enquanto relacionar algo a um valor significa reconhecer a determinação dos valores para os agentes históricos, isto é, constatar o fato da existência dos valores (BEISER, 2011, p. 412).

Os valores guiam o olhar do pesquisador, sem que sua opinião interfira na análise. Caso um cientista tome como objeto de estudo o varguismo, para voltar a esse exemplo, por mais que faça juízo negativo dos atributos políticos ou morais do fenômeno, ainda assim reconheceria a importância do estudo devido à significância que o fenômeno teve na formação de uma de toda uma nação. O estudo assim feito não está valorando, mas, segundo Rickert, se referindo a valores. Dessa forma concilia-se o reconhecimento do papel constitutivo dos valores na pesquisa histórica, sem perder a objetividade do conhecimento.

Herdeiro desse debate, Weber foi no mesmo sentido de justificar a utilização e a orientação da pesquisa por meio dos valores, apesar de sua origem subjetiva. O sociólogo emprega o que Beiser chama de "value-orientation", orientação valorativa da pesquisa (2011, p. 533). A noção de orientação valorativa, diz respeito ao processo de seleção do objeto de estudo histórico social. Frente à infinitude de elementos do devir que determinam um fenômeno e por ele são determinados o pesquisador se vê desnorteado, caso não se guie por critérios de relevância distintivos. De forma que um objeto se justifica de acordo com a significância que carrega para determinada cultura. Nesse sentido, afirma Weber,

\footnotetext{
Este caos [da multiplicidade dos fenômenos existentes] só pode ser ordenado pela circunstância de que, em qualquer caso, unicamente um segmento da realidade individual possui interesse e significado para nós, posto que só ele se encontra em relação com as ideias de valor culturais com que abordamos a realidade. Portanto, só alguns aspectos dos fenômenos particulares infinitamente diversos, e precisamente aqueles a que conferimos uma significação geral para a cultura, merecem ser conhecidos, pois apenas eles são objeto da explicação causal (2006, p. 54).
}

Interesse, valor, significância e subjetividade são integradas no itinerário da pesquisa social enquanto princípios de método e sem perder de vista a objetividade do conhecimento. 
Nesse sentido, fica claro que a proposta crítica na qual o sujeito está sempre implicado de forma parcial no objeto é plenamente absorvida por Weber.

\section{Considerações finais}

O presente artigo visou recuperar a memória da importante escola filosófica e epistemológica neokantiana. Para isso, remontou o contexto mais geral de ideias que possibilitou sua gênese, ressaltando os embates e os problemas teóricos que o conformaram. Desse modo, constatou que o movimento de retorno à Kant se deu em meio ao processo complexo de afirmação das ciências e da filosofia ao longo do século XIX. A polêmica contra o hegelianismo, positivismo, historicismo e naturalismo contribuiu para demarcar as respostas neokantianas à problemática do objeto das ciências e a validade de seu conhecimento. Argumentou-se que na busca de aprimorar a prática científica a escola neocriticista fundamentou a especificidade dos tipos saber.

Com foco nos representantes da escola de Baden, Rickert e Windelband, analisou-se o processo de formulação de conceitos com respeito ao esquema de categorização das ciências. Nesse sentido, apontou-se que o fim das ciências generalizantes são os conceitos em fórmulas universais que deem conta de explicar a relação causal entre certos fenômenos, como as leis de Newton. Por outro lado, as ciências individualizantes objetivam o conhecimento de um fenômeno em sua particularidade, tal qual o estudo de um fenômeno histórico. Entre estes polos, vale frisar, são dispostas todas as ciências, de acordo com sua afinidade com um ou outro extremo dessa linha. Demonstrou-se ainda o valor desse debate para Weber e como o sociólogo dele se apropriou para elaborar sua epistemologia própria da ciência da história e da cultura, alicerçado em ambos os caminhos, o generalizante e o individualizante. Pelo primeiro visava a explicação através da relação causal entre fenômenos, como a relação entre protestantismo e capitalismo; pelo outro intencionava a conceituação de um objeto individualizado, o capitalismo em sua particularidade, na diferença com outros sistemas.

Por fim, o artigo analisou a noção de valor em Rickert e sua função no estudo histórico. O filósofo distinguiu entre os juízos de valor e a referência ou relação aos valores, a primeira tem a ver com a elaboração de critérios de bem ou mal justo ou injusto, enquanto o segundo serve como meio de orientar o olhar do pesquisador em direção aos fatos dignos de apreensão. Desse modo, Rickert pretende resolver o problema do papel da subjetividade na pesquisa e concilia-lo com a objetividade do conhecimento. Mais uma vez, apontou-se que o debate neokantiano foi frutífero para Weber. O sociólogo valeu-se do conceito de orientação 
valorativa a fim de fundamentar os critérios de relevância para a seleção dos objetos de interesse na pesquisa histórica e cultural.

Espera-se que esse artigo possa trazer contribuições para a redescoberta das ideias da tradição neokantiana, assim como para o reconhecimento de seu papel na fundamentação das ciências sociais. Como possível desdobramento desse projeto pode-se vislumbrar a pesquisa das relações de outro grande sociólogo, cujo pensamento também é pouco reconhecido, Georg Simmel, com as ideias neokantianas. 


\section{Referências}

ALVES, A. A crítica de ponta-cabeça: sobre a significação de Kant no pensamento de Foucault. São Paulo, Revista Trans/Form/Ação, v.30, n. 1, pp. 25-40, 2007.

BEISER, F. The Genesis of neo-kantianism. United Kingdom: Oxford University Pres, 2014.

The German historicist tradition. New York: Oxford University Press, 2011.

FOUCAULT, M. Dits et écrits. Paris: Gallimard, 1994

FRIEDMAN, M; NORDMANN, A. The Kantian legacy in nineteenth-century science. Massachusetts: Massachusetts Institute of Technology Press, 2006.

HUGHES, J. A filosofia da pesquisa social. Trad. Heloisa T. Gomes. Rio de Janeiro: Zahar editora, 1980.

KÖHNKE, K. The rise of Neo-Kantianism. Trad: R. J. Holingdale. New York: Cambridge University Press, 1991.

LUFT, S. MAKREEL, R. Neo-Kantianism in contemporary philosophy. Indiana University Press, 2009

LUKÁCS, G. The Destruction of Reason. Trad. P. Palmer. London: Merlin Press, 1980.

SELL, C. Sociologia Clássica. Marx, Durkheim e Weber. Petrópolis: Editora Vozes, 2013.

VANDERBERGHE, F. As sociologias de Georg Simmel. Trad. Marcos Peres. Bauru: Edusc; Belém: EDUFPA, 2005.

WAGNER, G; HÄRPFER, C. Neo-Kantianism and the social sciences: from Rickert to Weber. In: WARREN, N; STAITI. A. New approaches to neo-kantianism. United

Kingdom: Cambridge University Press, 2015

WARREN, N; STAITI. A. New approaches to neo-kantianism. United Kingdom: Cambridge University Press, 2015.

WEBER, M. A "objetividade" do conhecimento nas ciêncas sociais. Trad. Gabriel Cohn. São Paulo: Ed. Ática, 2006.

WU, R. Heidegger e o neokantismo de Windelband e Rickert. São João Del Rei: UFSJ. Revista Estudos Filosóficos, n. 5, p. 174-186, 2010.

Recebido em 01-09-2017;

Revisado em 17-04-2018;

Publicação em 15-12-2018. 